\title{
Gastric Perforation, CTCAE
}

National Cancer Institute

\section{Source}

National Cancer Institute. Gastric Perforation, CT CAE. NCI Thesaurus. Code C143502.

A disorder characterized by a rupture in the stomach wall. 